\section{Fair comment}

\author{
Stephen Hancocks OBE
}

The trouble with 'fair' is that it is subjective. A fair day's weather for a sailor might be a lousy day if you are on the beach. What might seem like a fair deal to you may be a poor outcome to me and what could be deemed as fair trading to one customer and merchant could quite easily be judged an outrage by others. We are all vaguely familiar with the Office of Fair Trading (OFT) and their various reports on such subjects as mobile 'phone tariffs and the vagaries of energy supply companies and may even have a haunting memory of its report on private dentistry, published in 2003. It might therefore come as something of a surprise to learn that the OFT has just launched a new investigation into dentistry in the UK, this time including NHS dentistry.

On one hand, as a profession we might collectively raise our eyebrows and give a deep sigh at the prospect of yet more interference, more regulation and the potential placement of greater barriers to our actually being able to provide oral healthcare. However, it might be that in the interests of fairness the investigation could also help to clear the air, ostensibly for the consumer, since the OFT's mission is stated as 'to make markets work well for consumers. We achieve this by promoting and protecting consumer interests throughout the UK, while ensuring that businesses are fair and competitive' (www.oft.gov.uk), but in doing so, also for dentistry.

\section{THE IMPACT OF REGULATORY CHANGE}

Two of the eight aspects that the OFT indicated they would be focusing on, when they visited the BDA at the end of last month coinciding with the sudden announcement of this review, were "the impact of regulatory change: how it is or is not helping' and 'the availability of choice and impact of regulation on choice.' We, the profession, the BDA and the BDJ have been constructively and vigorously lobbying in recent years to explain the real and potentially negative effects on patient care occasioned by the cumulative enforcement of regulations from the Department of Health (DH) (notably the 'UDA' system in the current NHS contract in England and HTM 01-05) and the Care Quality Commission (CQC) as well as the various edicts, rumours and disquieting developments from the General Dental Council (GDC).

The previous OFT inquiry was sparked by a 'super complaint' by the Consumers' Association and a Which? report. However, it is, perhaps, curious that this new OFT initiative comes immediately on the tail of significant announcements last month on the competence of two of the above cited bodies.
The Council for Healthcare Regulatory Excellence (CHRE) is to investigate whether the GDC is fulfilling its statutory functions ('protecting patients' - GDC vs 'protecting consumer interests' - OFT) as has been requested by the DH. Meanwhile what the BDA described as a 'damning' review of the work of the CQC by no less than the House of Commons Health Select Committee criticises the distortion of the CQC's priorities by a statutory deadline to register dentists, and the Committee brands as 'astonishing' the fact that the CQC could ever have considered it sensible for small dental practices to be subjected to the same processes as large hospitals.

It is unthinkable that such evidence could be overlooked by the OFT in their exploration of the current marketplace. This does lead one to have some cautious optimism that any recommendations regarding competition that they make after March 2012, when their report is due (a tight timetable) may pave the way to some rational thinking as well as rationalisation of all these organisations apparently competing among themselves. Indeed, in the course of writing this editorial it has surprised me how many sets of acronyms I have had to list of bodies which should be synchronistic but in fact seem at worst to be preventing not oral disease itself but a route to effective prevention of oral disease; and this in the curtilage of a coalition government expressly campaigning to reduce quangos.

The OFT welcomes submissions from any interested parties (dentistry@oft.gsi.gov.uk) and as has been shown in other recent campaigns (the BDA's red tape campaign to name but one example), the greater the response the more notice is taken; so readers are encouraged to share their evidence of the real world of clinical dentistry and make their feelings known. Next Spring seems a long way off as we slide now into shorter days, longer nights and turning leaves but the deliberations of the OFT will make fascinating reading especially against the background of the new NHS pilots. There will doubtless be the long-standing, and palpably correct, repeated complaint that we as a profession do not communicate well enough with the public and with our patients. This will be fair and needs attention. The hope though has to be that overall some further good could come of such a comprehensive review. Yet after all these noble sentiments, laudable efforts at public and consumer protection and thousands of fine words it strikes me as horribly instructive that a 'search' for the words 'improving oral health' returns with the message 'not found'. How fair is that?

DOI: $10.1038 /$ sj.bdj.2011.824 